\title{
Tip I coronary artery ectasia in a patient with rheumatic heartvalve disease
}

\author{
Suleyman Surer*, Senol Yavuz, Faruk Toktaş \\ Deparment of Cardiovascularsurgery, Bursa Yüksek Ihtisas Education and Research Hospital, Bursa, Turkey
}

Email address:

drsuleyman1@ hotmail.com (S. Surer)

\section{To cite this article:}

Suleyman Surer, Senol Yavuz, Faruk Toktaş. Tip I Coronary Artery Ectasia in a Patient with Rheumatic Heartvalve Disease. Journal of Surgery. Vol. 2, No. 6, 2014, pp. 98-100. doi: 10.11648/j.js.20140206.14

\begin{abstract}
Coronary artery ectasia (CAE) is detected in approximately 1-5\% of all coronary angiography procedures. Coronary artery dilatation is only rarely diagnosed or cannot be recognized generally. There is no consensus regarding the definition of this rare anomaly. A 75-year old female who is a hypertansive and hyperlipidemia with a history of chronic stable angina despite full medical therapy. She was admitted on intensive care unit this time because of a typical chest pain that did not alleviate with sublingual nitroglycerin. Coronary angiography revealed mainly of the diffuse ectasia of three coronary artery and rheumatic heart valve disease. She underwent aortic and mitral replacement and a three-vessel bypass. Her postoperative course was well and she was discharged on the postoperative day $7^{\text {th }}$. The patient is doing well on follow-up with no recurrence of symptoms.
\end{abstract}

Keywords: Coronary Artery Ectasia, Coronary Angiography, Coronary Artery Bypass Grafting

\section{Introduction}

Coronary artery ectasia (CAE) is detected in approximately $1-5 \%$ of all coronary angiography procedures. Angiographically, a CAE is defined as a coronary artery segment that has a 1.5 times greater diameter than that of a healthy segment [1-3]. In patients with coronary artery disease and coronary artery dilatation is only rarely diagnosed or cannot be recognized generally [2]. There is no consensus regarding the definition of this rare anomaly. Coronary artery ectasia (CAE) and coronary artery aneurysm (CAA) manifest themselves with an abnormally dilated coronary vessel.

Both the entire length and a part of a coronary artery may be involved. Blood flow in the ectatic portions of the coronaries may become slowed, a condition that may well lead to effort angina or frank myocardial infarction independent of coexisting coronary stenoses.

\section{Case Report}

A 75-year old female who is a hypertansive and hyperlipidemia with a history of chronic stable angina despite full medical therapy. The patient did not have a history of smoking and did not abuse alcohol.She was admitted on intensive care unit this time because of a typical chest pain that did not alleviate with sublingual nitroglycerin. On physical examination, her blood pressure was 105/50 mm Hg and his heart rate was 65 beats/min. The plasma levels of total cholesterol,triglyceride and low-density lipoprotein cholesterol were 155,110 and $80 \mathrm{mg} / \mathrm{dL}$, respectively. Other biochemistry and blood tests were within normal limit.Her 2D echocardiography (2D Echo) showed mitrale regurgitation (III degree) and aortic regurgitation (III degree) .Her coronary angiography showed left anterior descending (LAD) of $\% 70$, circumflex coronary artery of $\% 60$ and right coronary artery of \%60 stenosis occured.Coronary angiography revealed severe CAE,mainly of the diffuse ectasia of three coronary artery and rheumatic heart valve disease(F1g1,2). The patient was referred to our clinic for surgical management. She underwent aortic and mitral replacement because of mitral valve repair was unsuccessful and a three-vessel bypass using the left internal mammary to the left anterior descending and reversed saphenous vein grafts to the obtuse magrin and the posterior descending coronary arteries. Her postoperative course was well and she was discharged on the postoperative day $7^{\text {th }}$. One hundred $\mathrm{mg}$ of aspirin and $5 \mathrm{mg}$ of warfarin daily were prescribed. The patient is doing well on follow-up with no recurrence of symptoms. 


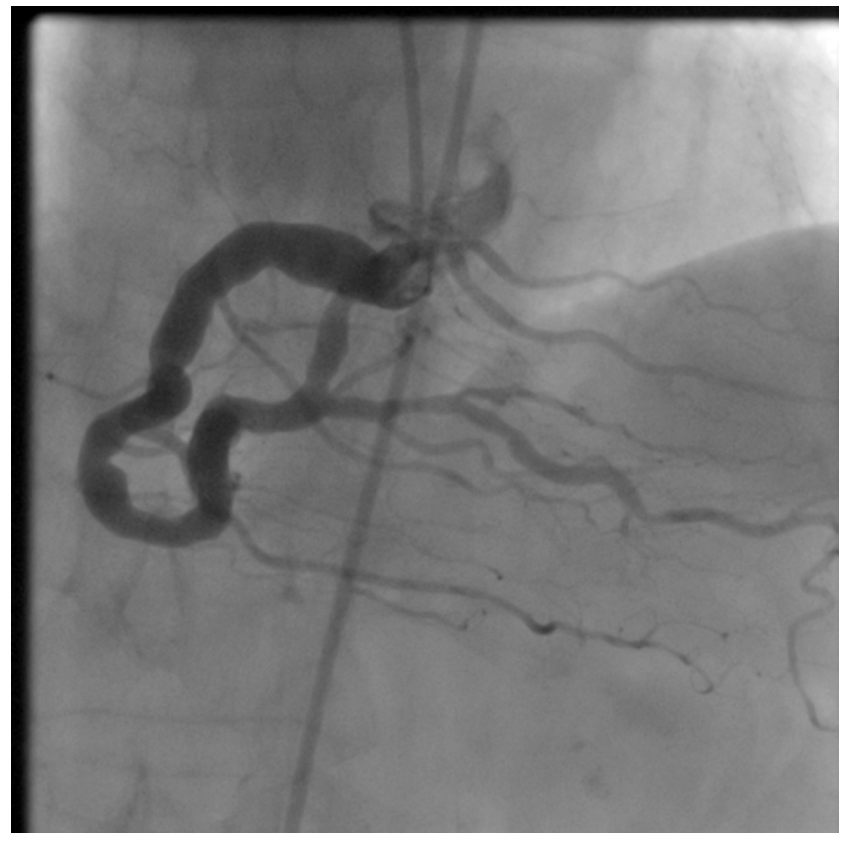

Figure 1. Coronary angiography of the left anterior descending and circumflex coronary artery showing a diffuse ectasia involment.

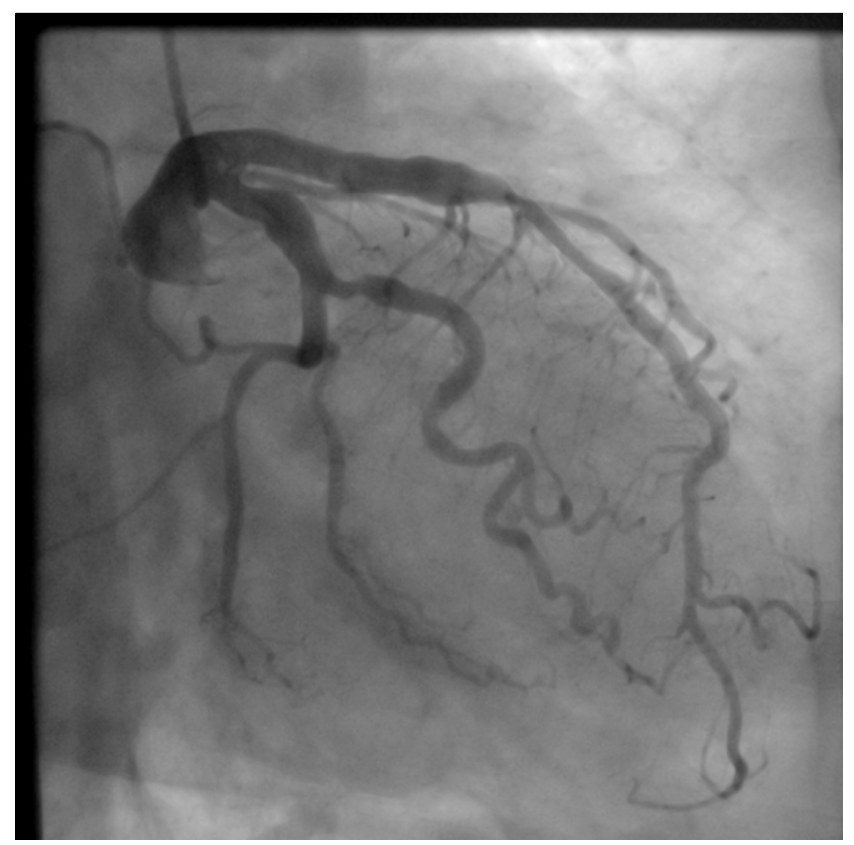

Figure 2. Coronary angiography of the right coronary artery showing a diffuse ectasia involment.

\section{Discussion}

Despite being uncommon, CAE has increasingly been more encountered ever since coronary angiography has been introduced into clinical practice. In most patients $\mathrm{CAE}$ or CAA are found in the context of the coronary artery disease. The etiologic factors for CAE development include atherosclerosis, connective tissue diseases including Marfan syndrome and Ehlers-Danlos syndrome, conditions with arterial inflammation such as systemic lupus erythematosus or Takayasu's arteritis, percutaneous coronary interventions, infections including endocarditis, syphilis, vasculitic disorders, and Kawasaki disease. CAA can be congenital in a minority of patients[2,4]. Congenital and acquired forms of coronary aneurysms pose a challenge with respect to their differentiation from each other even after other causes leading to coronary aneurysms are excluded. Coronary ectasia in the context of severe coronary artery disease is treated with coronary artery bypass surgery. By far there is no single definition of this disorder. A number of classification schemes have been proposed to classify CAA. These may be based on the anatomical shape of the ectasia (fusiform vs.saccular forms), the architecture of the aneurysm wall (true aneurysm vs.pseudoaneurysm), and size of the aneurysm (e.g., large or giant aneurysms) [2].

CAE may be classified into four types on basis of the extent of coronary artery involvement:

Type I - diffuse ectasia of two or three vessels;Type II diffuse ectasia in one vessel and localised disease (ie, aneurysm) in another;Type III - diffuse ectasia in one vessel only, and;Type IV - localised or segmental involvement (CAA) only[3].

This classification may have prognostic implications, with the worst outcomes in types I and II [2].

CAE is defined as a diffuse dilatation of the coronary vessel that measures 1.5 times greater than the healthy segment and affects at least $50 \%$ of the entire coronary artery length. CAA, on the other hand, is a local dilatation of coronary artery that has a diameter greater than that of the neighboring segments or 1.5 times the largest coronary vessel. The coronary artery is involved in less than $50 \%$ of its entire length[2-4]. A giant aneurysm is defined as one where the maximal vessel diameter exceeds $20 \mathrm{~mm}$ in adults or $8 \mathrm{~mm}$ in children. In adults, the reported diameter of giant CAAs varies from 50 to $150 \mathrm{~mm}$. Giant CAAs are rare, with a reported prevalence of $0.02 \%[5,6]$.

Gunes et al. reported that RCA was the most commonly involved artery and simultaneous involvement of RCA and circumflex arteries was common in isolated CAE cases[7].

Coronary angiography is the mainstay of the diagnosis of CAE. IVUS, on the other hand, perfectly fits for assessment of luminal size and vessel wall. It can reliably distinguish true from false aneurysms caused by atherosclerotic plaque rupture. CAE is characterized by impaired filling and washout of the affected segment, with the severity of both being closely related to disease severity. One disadvantage of CAE follow-up is the need for repeated coronary angiography examinations. Three dimensional, non-contrastenhanced, free-breathing coronary magnetic resonance angiography (MRA) allows for detailed analysis of the proximal and mid portions of left main, left anterior descending, and right coronary arteries [8].

MRA, as compared with CTA, has the additional advantages of not requiring ionizing radiation or contrast agent. Even more attractive is the ability of MRA,when combined with coronary flow data, to give information whether the aneurysmatic segment has been blocked by 
thrombus formation[9]. As a noninvasive technique without radiation, it is a well-suited follow-up technique for such patients.In near future it may be possible to cut down the radiation dose required for CTA. The exact etiology of CAE should be delineated by clinical, histopathological and pathophysiological examinations. Patients with coronary stenoses with signs or symptoms of severe ischemia despite maximal medical treatment can be successfully managed with percutaneous and/or surgical coronary vascularization. CAEs have a potential to cause cardiac tamponade by rupturing into pericardial space, as well as thrombosis, embolization, dissection, mechanical obstruction, or erosion and fistula formation between adjacent anatomical tissues. Surgery is the treatment of choice in such patients to prevent devastating complications [10]. Coexistence of significant coronary stenosis and CAE requires coronary artery bypass grafting in majority of patients. The operational techniques may include ligation of aneurysm or resection or marsupialization with interposition graft; however, the ideal technique remains to be proven $[11,12]$.

Inconclusion, the treatment for coronary artery ectasia are stil controversial.Patients with CAE can be managed in a more efficient manner with advent of novel methods for noninvasive imaging of coronary tree as well as introduction of effective modern antiplatelet and/or vasoactive drugs into clinical practice. We propose that post-stenting aneurysms (with or without coronary stenosis), expanding aneurysms/ pseudonaneurysms and symptomatic aneurysms should be surgically treated.

\section{Conflict of Interests}

All authors have no conflicts of interests to disclose. The authors do not have a direct financial relation with any commercial identities mentioned in the paper.

\section{References}

[1] Singh SK, Goyal T, Sethi R, Chandra S, Devenraj V, Rajput NK et al. Surgical treatment for coronary artery aneurysm: a single-centre experience. Interactive CardioVascular and Thoracic Surgery 2013; 17(4):632-7.

[2] Díaz-Zamudio M, Bacilio-Pérez U, Herrera-Zarza MC, Meave-González A, Alexanderson-Rosas E, Zambrana-Balta
GF et al.Coronary artery aneurysms and ectasia: role of coronary CT angiography. Radiographics 2009; 29(7):19391954.

[3] Yavuz S, ErisC , Surer S Toktas F.eComment:Coronary artery dilatation: Ectasia or aneurysm.Interactive CardioVascular and Thoracic Surgery2013;17(4):636.

[4] Markis JE, Joffe CD, Cohn PF, Feen DJ, Herman MV, Gorlin R. Clinical signifi-cance of coronary arterial ectasia. Am J Cardiology1976; 37(2):217-222.

[5] Bajaj S, Parikh R, Hamdan A, Bikkina M.Covered-stent treatment of coronary aneurysm after drug-eluting stent placement: case report and literature review. Texas Heart Institute Journal2010; 37(4): 449-454.

[6] Li D, Wu Q, Sun L, Song Y, Wang W, Pan S et al. Surgical treatment of giant coronary artery aneurysm. Journal of Thoracic and Cardiovascular Surgery2005; 130(3):817-821.

[7] Y Gunes, B Boztosun, A Yildiz, A Metin Esen, M Saglam, M Bulut et al . Clinical profile and outcome of coronary artery ectasia.Heart2006; 92(8):1159-1160.

[8] Bluemke DA, Achenbach S, Budoff M, Thomas C, Gerber TC, Gersh B et al. Noninvasive coronary artery imaging: magnetic resonance angiography and multidetector computed tomography angiography: a scientific statement from the American heart association committee on cardiovascular imaging and intervention of the council on cardiovascular radiology and intervention, and the councils on clinical cardiology and cardiovascular disease in the young. Circulation2008; 118(5):586-606.

[9] Mavrogeni SI, Manginas A, Papadakis E, Foussas S Douskou E, Vieskelis P. Correlation between magnetic resonance angiography (MRA) and quantitative coronary angiography (QCA) in ectatic coronary vessels. Journal of Cardiovascular Magnetic Resonance2004;6(1):17-23.

[10] Tiryakioglu O, Basel MC, Tiryakioglu SK, Turk T, Yavuz S. An emergency surgical repair for ruptured giant right coronary artery aneurysm. Turkish Journal of Thoracic and Cardiovascular Surgery2008; 16(2):120-121.

[11] Harandi S, Johnston SB, Wood RE, Roberts WC. Operative therapy of coronary arterial aneurysm. American Journal of Cardiology1999; 83(3):1290-3.

[12] Meraj PM, Makaryus AN, Boxt LM. An unusual combination of myocardial bridging and coronary artery aneurysm identified on 64-detector coronary angiography. International Journal of Cardiovascular Imaging2007; 23(5):649-653I. 